\title{
The Core and Key Points to Deepen the Administrative System Reform
}

\author{
Miaomiao $\mathrm{Hu}$ \\ Hubei Business College \\ Hubei, China
}

\begin{abstract}
Going with the continuous development of modernization in China, the government affairs have lower work efficiency due to its defect under traditional systems, which have been exposed. So it has become increasingly important and urgent to reform the government affairs management and administrative flows. Currently it needs to summarize and defects of government affairs, keep logical and effective administrative flows and develop new administrative work flows on the basis of the existing. For the power distribution in the administrative work, it needs to carry out a more reasonable program, such as the separation of multiple powers. This article mainly show key points for the government affairs flow changes.
\end{abstract}

Keywords-governmental affairs management; administrative flow changes; separation of multiple powers

\section{INTRODUCTION}

Lower efficiency of the existing social administrative functions and flows has been a barrier which seriously hinders the development of administrative affairs and people's livelihood, facing with such as situation, it needs to optimize and improve the existing administrative affairs. The optimization of administrative work can not only improve the efficiency of the government affairs, but also upgrade the soft strength of the government agencies and respond to the drastic changes at home and abroad, and provide great support to China's prosperity and rise. The changes in administrative affairs flow shall be focused on the people's livelihood, defense, economy as well as the improvement of efficiency in administrative services.

\section{IMPORTANCE FOR THE ADMINISTRATIVE SYSTEM REFORM}

\section{A. Important forInternationalized Development}

The changes of administrative affairs flow shall be based on the basic administrative situations in China but also borrow the proved modes of international administrative flows, which shall not be separated from international societies, borrow whatever it will do good but reject whatever it will do harm, so as to create a new administrative affairs flow with Chinese characteristics. The innovative administrative affairs flow shall be based on the socialism but not be westernized only because of borrowing what is thought to be good from foreign countries, whether it is innovated or borrowed, we must insist on the administrative basis of China. After reform, the administrative affairs flow shall be able to improve the efficiency of administrative staffs and better introduce China toward and into the world, so as to keep up with the development of the era and become powerful gradually.

\section{B. Important for Internal Development}

When changing the administrative affairs flow and borrowing those from foreign countries, the reformers should pay more attentions to the influence of the reformed administrative flows. It is true that external causes are important, but the internal cause is the root of a thing. For the newly reformed government affairs flows, pilot operation shall be done in some government units at home to observe the actual operational performance, which may efficiently and early discover the defects in the administrative affairs flows and make improvements so as to form proved official document rules in practice. In a word, the reformed administrative affairs flows shall undergo the tests of foreign and domestic factors.

\section{Transform the Highly Centralized Management System}

Since China's foundation, though many parties are supported to discuss state affairs, in fact, we still carry out the one-party system where the Chinese communist party is predominating, and the over centralization has caused more and more problems. (1) The most serious consequence of the one-party system is that whether the words of the people will work or not have to depend on their positions, those who have no positions or relationships feel hard to pass their opinions to the upper class, which may be what the people want. The status quo where a minority controls the political directions often causes serious political errors and even endangers the country. (2) The one-party system will greatly affect the economy, culture and society and even take measures to ban those that are against the political ideology of the party. (3) It will cause low efficiency of government affairs, and even it can be done only through the backdoor and money bribes. (4) One-party system may cause no adequate opinions got from most people. For any problem arising out of the government affairs, no one appears to bear relevant responsibilities and most just shuffle. Facing such a situation, it is extremely important to improve the defects and deficiency of the government affairs flow. 


\section{KEY POINTS OF ADMINISTRATIVE MANAGEMENT SYSTEM REFORM}

\section{A. Transformation of Administrative Management System}

Since the foundation, China has been insisting on the way for development with Chinese characteristics, borrowing western experience to push the economic development in the country, and Chinese culture is well combined with the western world, both Chinese-style leadership and western concepts are adopted to handle government affairs in the country. China is developing continuously, and becoming stronger and stronger relying the rich cultural deposits and subsequent learning ability, up to now, it has revived as a great nation throughout the world. Though in the past more than one hundred years, Chinese history has been filled with blood and tears, yet it has revived again. We are in a new era where every country around the world is in a great change, what China should do is to catch the chance, overcome all difficulties and create the brilliance of its own. In order to improve the government affairs level in the country, it has to depend on the people, doing for the people and by the people. The people are the foundation of a nation, and the politics have to depend on the majority for decision making in the country, which is the truly well going politics, but not controlled completely by a few, otherwise, it may cause narrow eyesight or even improper decisions, leading the country to a wrong way. Currently the multi-party system in the US can be borrowed, and the one-party system may make it difficult for decision makers to see through facts, which can be seen from the dictatorship of emperors in the feudal society. After all, no one is absolutely perfect, and all things have to be negotiated for settlement. In addition, the people shall have their presence shown in the country, who have requirements to execute the rights of their own, only as such, can the people have judgments of their own, but not be fooled, think nothing and even cannot see right from wrong.

\section{B. Perfect the Socialist Administrative System}

The participation of all the people in politics can be traced back to the ancient Greek, which is a so-called democratic politics, though there were defects, yet acting as the first democratic politics, it showed a trend for development in the future. The political flows in Chinese government affairs are expected to strengthen the interaction with the people, attracting the public to participate and making them feel the political culture and philosophy in heart, a country where the people are administrated under laws can be called a rule of law country. What the governments should do is to clarify the governmental powers and decentralize the governmental affairs, which needs to streamline institutions and improve the skills and efficiency of handling government affairs. In addition, we must have sound legal restraints and specific supervision over parties or sectors so as to further promote the work of government sectors, making the staffs incorruptible so as to benefit the people.

\section{Intensity the Construction of Democracy and Rule of Law}

Whether the people have legal consciousness and ideas or not is an important indicator for a country to become a rule of law country. The work of the government public affairs shall firstly make political activities open to the people, who can better absorb the essence of the rule of law to form a legal concept. Besides, the democratic thinking and self-awareness that the people hold is also a basic security to a country to own civilization and human rights. As a country under rule of law, China has been striving to make all the people have legal awareness and supervision over the government.

\section{Empower and Decentralize Powers Rationally}

Logical decentralization of powers is an important indicator for a country whether it is mature in politics. China has been insisting on the one-party system, keeping unchanged never, which can be proved by the centralization system of emperors in the feudal society. Only the decentralization in politics in the country can push it to a healthy way for development, help to handle basic problems, people's livelihood, social problems and the macro economy, and promote the development of all industries across the country. Since the foundation, the most painful lesson is what we got from the Cultural Revolution, which actually was caused by the blind worship to leaders under the one-party system, which is painful but beneficial. In order to upgrade the politics to a higher level and find a way healthy and steady for development, it has been becoming more important to borrow the advanced political forms and philosophies in west countries. To borrow the political philosophies and separation of multiple powers is not to overturn the Chinese politics or completely change it, it only aims to get the strengths of other countries to improve our own and finally create a way with Chinese characteristics and rule of laws suitable for China only. The facts in history have proved that the decentralization in political rights may run better than the one-party system as an advanced political ideology and form. One-party system may cause no adequate opinions got from most people. The separation of multiple powers may optimize and better predict the state political activities for the government form which consists of government power executing departments, political decision making departments and political supervision departments, which is not controlled by a few people under the one-party system; if the politics in a country is determined by the emotions and attitudes of a few people, the country will go out of the expectation of the most people.

\section{E. Reform and Innovation of Administrative Systems}

All things outdated shall be rejected so as to adapt to the development of the era and rejuvenate its vitality, so is the politics. Currently the government affairs departments are fragmented and dispersed in distribution, and the functions of administrative departments are unclear, overlapped or disturbed each other, which finally lead to a series of problems such as low work efficiency and disorder in government affairs departments. With the development of the era, the work of government departments are facing with many challenges, only to optimize the government systems, improve the efficiency of departments and remove some tedious and unnecessary departments as well as office procedures can the current political environment in China regain a new life. While conducting the changes, we should be active to attempt, doing some new work flows in governmental affairs, which may 
place a solid foundation for the development of government departments in the country.

The government work reports and whole work flows shall be open to the public, and each citizen is promoted to have senses of rule of law and being masters. And the citizens should be encouraged to execute the rights they own and participate in all kinds of political activities so that the work of governmental departments will become more efficient and persuasive.

\section{F. Optimize the Governmental Structure}

To optimize the governmental structure is to reject the illogical and inefficient departments in the governmental structure and make targeted reorganization and transformation. The departments which have no functions or performances should be rejected as early as possible, and the departments with great potentials needing to develop shall be vigorously pushed and advocated, which can not only improve the work efficiency of government departments, but also reduce the costs of the state on government affairs, and the costs will be used where it needs, in addition, it can encourage the rational competition among the government departments, where there is competition, where there will be progress. In the meantime, the separation of multiple powers shall be encouraged, and oneparty system has been proved unsuitable in history and far to meet the trend of the era. Maybe, the multi-party system and reasonable decentralization can work better and bring good decisions and policies to the people.

\section{Key POINTS FOR THE AdMINISTRATIVE SySTEM REFORM}

The ultimate purpose of whether the government affairs flow or the governmental policies is to improve the work efficiency and create more benefits and security for the people. The government is always insisting on the political concept of going, developing and staying with the people, for the people are carriers of the country. In the meantime, the state insists on the opening and borrowing the essences from the western business model, political model and culture, but not deviating from the principle of a socialist way with Chinese characteristics. And the government affairs shall be open and apparent like the west, and insist on exposing the ruling procedures of the party and government to the public who will become proud of the politics and confident of the country, and the concept of a country, rather than a family will be shown.

\section{A. Key Points for Administrative Procedures Reform}

A feasible method or strategy can effectively optimize and improve the routine government affairs work. The government is the largest ecological environment of a country, and the government affairs shall be open and transparent, all government expenditure, infrastructure investment and foreign trade exchanges shall be shown completely and clearly before the public, with nothing concealed. As such, we can improve the credibility of the government and enhance the trust and sense of security of the people to the government agencies and public servants. Second, acting as a large political and ecological environment, the government shall not only handle affairs through the hereditary system but also can not always appoint incompetent public servants, as an ecological environment, it should be kept competitive and the public servants shall be assessed regularly, keeping the qualified and reject the disqualified, so as to stabilize the state political environment and keep continuous breakthrough and optimization.

\section{B. Key Points for Administrative and Technical Reforms}

Nowadays, we have entered an era of Internet, big data and even the artificial intelligence. And the government agencies have to follow the trend of the times, striving to learn the technologies and culture in the trend so as to improve the political service level and office efficiency. At present, the popularity of the Internet and the continuous development of the Internet of things have brought the governments opportunities to create information platforms of their own, through which, the people may get the work information and access to the first information, which may be very important for the people. It can not only help to get rapid information but also make the government work progress open and transparent.

\section{Key Points for Strategic Reform to Transform Governmental Functions}

The government affairs flows shall be kept open and transparent to the public so as to enable the people clearly understand the whole administrative flows and duties of the governments, and the duties of the public as citizens needing to fulfill. The government affairs flows shall be simplified, keeping those essential and proved, rejecting those fussy and outdated so as to improve the work efficiency of the governments. Functional departments of the governments shall be responsible for the overall situation, and make a strategic arrangement on the work over the year, and conduct follow-up and investigation at any time on the people's livelihood, macro economy and social issues, carry out control and adjustment when necessary so as to guarantee the gradual completion of the yearly plan.

\section{CONCLUSION}

That the governments keep the government affairs open and transparent will help strengthen its relations with and gain the trust of the people, which benefit both the people and the country. In addition, the one-party system shall be gradually transformed into a multi-party system, and the political form where the people are masters of the country is also a progress of the Chinese politics. To insist on the separation of multiple powers rather than the one-party system will help to stabilize the government affairs and political forms. To continue perfecting laws and improve the work efficiency of the governments will help to stable the local government and ultimately the central government, which are what the people and public servants have been expecting.

\section{REFERENCES}

[1] Tang Haolin, Researches on Ways to Build an Incorruptible Government in the New Period[D].Southwest University, 2014: 1-3. 
[2] Wen Hong, Xie Yahong, Strengthen Researches on Administration to Push the Government System Reform-2011 Annual Conference of Chinese Public Administration Society \& "Strengthen Researches on Administration to Push the Government System Reform" Academic Forum [J]. Chinese Public Administration Society, 2012, 01:123-125.

[3] Song Yaqin, Wang Youqiang, Zhang Nan, Strategic Reflection of Administrative System Reform from the Perspective of Government Performances - on the basis of investigation on public servants in local governments[J]. Journal of Public Management, 2012, 04:1-11+122.

[4] Xue Rui, Analysis of Hidden Elements in the Administrative System Reform [J].Chinese Public Administration, 2010, 05:19-22.

[5] Lin Lin, Researches on Reform Modes of Chinese Administration System in the New Period[D]. Shandong Polytechnic University, 2010: $1-2$

[6] Lyu Lei, Discussion on Setting up an Incorruptible and Efficient Government on the Background of Administrative System Reform[J].Reform \& Opening, 2010, 22:26+28.

[7] Topic Group of National Academy of Education Administration, Researches on Service-Oriented Government Providing Educational Products \& Administrative System Innovation [M]. Guangzhou: South China University of Technology Press, 2010.

[8] Zhou Tianyong, History and Trend of Administrative System Reform in China [J] Journal of the Party School of CPC Zhuhai Municipal Committee and Zhuhai Administration Institute, 2009, 05:16-20+30. 